\title{
Administratieve organisatie van afvalstoffen in produktiebedrijven
}

Drs. J. L. P. Piet

\section{Inleiding}

Het gaat niet goed met ons milieu.

De Regering heeft in de Notitie 'bedrijfsinterne milieuzorg'1 de Tweede Kamer aangegeven dat er in ons land 10.000 tot 12.000 bedrijven zijn met een zware (potentiële) milieubelasting, die een integraal milieuzorgsysteem zullen moeten toepassen, en circa 250.000 bedrijven met een beperkte milieubelasting die dit systeem partieel moeten invoeren. Een milieuzorgsysteem is een samenhangend geheel van beleidsmatige, organisatorische en administratieve maatregelen, gericht op het inzicht krijgen in, het beheersen van en waar mogelijk het verminderen van de effecten van de bedrijfsvoering op het milieu. Zo'n systeem bevat naast technische en milieuhygiënische aspecten ook elementen, die liggen op het terrein van het vakgebied van de administratieve organisatie (ook genaamd 'bestuurlijke informatieverzorging' en hierna te noemen het 'vak AO'). Ook vanuit het vak $A O$ kan een bijdrage worden geleverd. Eén van de onderwerpen welke in dit kader kunnen worden bestudeerd, is de organisatie en beheersing van de afvalstoffenstromen. Dit artikel zal dit vraagstuk zowel vanuit de theorie van de administratieve organisatie benaderen als vanuit de praktijk van bedrijven die afvalstoffenstromen kennen. Nadrukkelijk stellen wij vooraf dat de in dit artikel genoemde oplossingen niet in de plaats zullen treden van de bestaande milieutechnische beheersingssystemen, doch hierop een aanvulling geven.

Wij zullen een illustratie geven van de beheersing van milieugevaarlijke afvalstoffen, die in vaste of vloeibare vorm in een bedrijf vrijkomen en op milieuhygiënisch verantwoorde wijze moeten worden verwerkt. Niet zal worden ingegaan op de milieugevaarlijke stoffen die via emissies in de lucht of in het water vrijkomen, omdat identificatie en meting van deze stoffen, en daarmee de interne controle hierop veelal complexer is. Een beperking wordt ook aangebracht in de doelgroepen zoals deze worden onderscheiden in het Nationaal Milieubeleidsplan. ${ }^{2}$ Wij behandelen hier het afvalstoffenvraagstuk zoals dit bestaat in de industrie. In een volgend artikel zal nader worden ingegaan op de controle op de afvalstoffen in de bedrijven die werkzaam zijn in de afvalstoffensector.

Ten slotte wordt de beschouwing beperkt tot de beheersing van de stoffenstromen op operationeel niveau en zullen de strategische vraagstukken zoals de ontwikkeling van nieuwe produkten welke duurzamer zijn of minder afval genereren, en de ontwikkeling van nieuwe, milieuvriendelijke produktietechnieken, buiten behandeling blijven.

Het doel van het vak $A O$ is een model te geven van de wijze waarop een bedrijf qua informatieverzorging moet zijn georganiseerd ten behoeve van het besturen en doen functioneren van het bedrijf en ten behoeve van het afleggen van verantwoording over het gevoerde beleid. Toegepast op het

Drs. J. L. P. Piet, registeraccountant, is kantoorpartner TRN Groep/Nederlandse Accountants Maatschap de Tombe, docent Bestuurlijke Informatieverzorging Universiteit Amsterdam, directeur Wetenschappelijk Instituut voor Milieu Management Envicon. 


\section{MAB}

afvalstoffenvraagstuk zijn dan de belangrijkste vragen, welke moeten worden beantwoord:

- welke informatie is nodig om de bedrijfsprocessen aan te sturen en te beheersen waarbij afval ontstaat en wordt afgevoerd;

- welke informatie is nodig voor het afleggen van verantwoording over de bedrijfsactiviteiten waarbij afvalstoffen zijn betrokken.

Ten behoeve van de voorziening in informatiebehoeften besteedt het vak administratieve organisatie aandacht aan het aspect van interne controle: hoe houdt het bedrijfsmanagement de bedrijfsprocessen, waarbij afval is betrokken, onder controle en hoe betrouwbaar is de informatie hieromtrent? Juist het controle-aspect binnen het vak administratieve organisatie is hier interessant, omdat dit aansluit op de maatschappelijke behoefte om de milieuvervuiling onder controle te krijgen.

In het vak $A O$ is de beheersing van de 'normale' goederenstroom een diep uitgewerkt thema. Bij afvalstoffen treden echter belangrijke verschillen op. In tegenstelling tot normale goederen worden afvalstoffen meestal niet begeerd; zij hebben veelal een negatieve waarde voor de bezitter. Dit heeft consequenties voor de wijze waarop deze stoffen zullen worden bewaard en bewaakt. Om te kunnen beoordelen of, en zo ja in welke mate de stoffen schadelijk zijn, is deskundigheid nodig van natuurwetenschappen. Dit is een ander referentiekader dan dat van de bedrijfseconomie. Afvalbeheersing is vanuit de optiek van de informatieverzorging een totaal nieuw fenomeen.

De vragen die wij in dit artikel willen beantwoorden zijn:

1 kunnen bedrijven milieugevaarlijke afvalstromen adequaat besturen en onder controle houden?

2 kan het vakgebied van de administratieve organisatie een bijdrage leveren aan de bedrijfsinterne milieuzorgsystemen en de beheersing van afvalstoffen binnen bedrijven?

3 kan door bedrijven verantwoording worden afgelegd over het gevoerde milieubeleid ten aanzien van afvalstoffen?

\section{Wat zijn afvalstoffen?}

Afval ontstaat bij de produktie van stoffen of goederen welke voor de markt zijn bestemd. Zowel stoffen die het produktieproces ingaan en geen bestanddeel uitmaken van het eindprodukt (zoals snijrestanten en hulpstoffen) als de afgekeurde eindprodukten (in de bedrijfseconomische theorie aangeduid als 'uitval'), kunnen afval opleveren. Milieugevaarlijk afval treedt niet alleen in de chemische industrie op, maar ook in andere bedrijfstakken ontstaan voor het milieu onvriendelijke reststoffen (raffinaderijen, veehouderij). Als voorbeeld zullen wij de produktie van chemische bulkstoffen uitwerken.

Afval kan waarde hebben. De bezitter zal dan met een zekere zorg zijn bezit bewaken en trachten een maximale opbrengst te verkrijgen met recycling of verkoop ervan. Bij de produktie van sommige kunststoffen bijvoorbeeld ontstaan reststoffen, die binnen de fabriek kunnen worden hergebruikt omdat de kosten van omwerking tot grondstof lager zijn dan de kosten van aanschaf van nieuwe grondstoffen. Deze constellatie past redelijk binnen de bekende theorieën van de economische wetenschap en behoeft hier nauwelijks uitwerking, zodat wij ons hier zullen beperken tot de afval met negatieve waarde.

Indien hoge kosten moeten worden gemaakt om afval te verwijderen, te behandelen of te vernietigen dan moeten wij er een negatieve waarde aan toekennen. Voor de bezitter is afval geen activum, doch een voorziening op de balans welke verband houdt met de kosten van afvoer en vernietiging. De producent van afval zal zich daarom bij de aansturing van de produktieprocessen mede kunnen richten op de beperking van de afvalkosten.

Dat deze schadelijke stoffen voor de bezitter een negatieve waarde hebben wordt hem door de overheid opgelegd. Bij het ontstaan van milieuproblemen is er sprake van afwentelingsmechanismen. ${ }^{2}$ Onjuist behandeld afval leidt tot de afwenteling van kosten naar een ander schaalniveau (bijvoorbeeld van locaal naar regionaal), naar andere groepen van de samenleving, of naar toekomstige generaties. De ordening van het 


\section{MAB}

economisch leven volgens het marktmechanisme werkt niet omdat er geen markt mogelijk is tussen de vervuiler en de gedupeerde. Wettelijke voorschriften verplichten de bezitter van milieuschadelijk afval daarom tot een bepaalde wijze van afvoer en vernietiging volgens het uitgangspunt dat 'de vervuiler betaalt', en de overheid houdt hierop zicht door een stelsel van vergunningen en middels inspecties, toezicht en handhaving.

Omdat de naleving van de wettelijke voorschriften een druk geeft op de winstgevendheid en de concurrentiepositie van bedrijven, is er een latent gevaar dat de wet wordt ontdoken. Ook is het denkbaar dat de zo gevreesde 'milieu-maffia' schadelijke stoffen tegen betaling overneemt en deze illegaal stort of vermengt met andere produkten (bijvoorbeeld de vermenging van PCB's met stookolie) zodat deze alsnog hun schadelijke invloed op het milieu zullen hebben. Om strafrechtelijke vervolging of mogelijke schadeclaims te vermijden en om de negatieve publiciteit, die aan milieudelicten is verbonden te ontgaan zullen de bonafide bedrijven zich in beginsel bereid tonen vrijwillig een goed opgezet intern milieuzorgsysteem te ontwikkelen met een goede administratieve organisatie. ${ }^{4}$ De overheid acht het de eigen verantwoordelijkheid van het bedrijfsleven om met maatregelen te komen en stimuleert deze ontwikkeling. 5,6

Het niet naleven van milieuvoorschriften kan grote financiële risico's met zich brengen, die ook voor de financiële verantwoording van de bedrijven (de jaarrekening) van materieel belang kunnen zijn. ${ }^{7}$ Zowel bij de samenstelling van de jaarrekening als bij de accountantscontrole ervan wordt gesteund op een toereikende organisatie van de interne controle. Daartoe zal ten aanzien van het afvalstoffenvraagstuk ook een goede interne organisatie moeten bestaan.

Hoe giftiger een stof, des te hoger is de noodzaak om deze stof onschadelijk te maken. De toxiciteit is aldus, via de wettelijke maatregelen, van invloed op de prijsvorming van de afvalverwerking. De andere prijsbepalende factor bestaat uit de bedrijfskosten van de afvalverwerking zelve. In theorie lijkt hier dus een evenwicht mogelijk op de markt van afvalstoffen. Binnen ons huidige referentiekader waarin wij ons een oordeel kunnen vormen omtrent de (on)wenselijkheid van afval, treffen wij echter veel aspecten aan, die een nadere invulling behoeven. Het milieuverschijnsel is te nieuw om alle aspecten te kunnen overzien.

Uitgaande van de vooronderstelling dat de kosten van de verwerking van afval lager zijn dan de schadelijke effecten, zullen wij de verwerkingskosten kunnen hanteren als prijsgrondslag voor de afvalstoffen. Deze prijs kan in de administratie worden gehanteerd als een vaste verrekenprijs waarmee het verloop van de fysieke afvalstromen kan worden uitgedrukt in financiële termen. Aldus wordt het mogelijk om de voorraad en voorraadmutaties in de afvalstroom intra-comptabel te volgen, zoals ook gebruikelijk is bij de goederen met een positieve waarde.

\section{Beheersing van bedrijfsprocessen}

De doelstelling van de interne controle op de afvalstoffen bestaat uit het voorkomen dat deze stoffen op de verkeerde plaats terechtkomen. Dit sluit aan op het algemene maatschappelijke belang waarin de milieuzorg is gericht op de vraag of alle milieugevaarlijke stoffen op de juiste wijze zijn verwerkt. Het milieuzorgsysteem binnen het bedrijf zal met name gericht moeten worden op de twee volgende hoofdrisico's:

$1^{\circ}$ het ontstaan/de verwerving van afval is niet volledig in de administratie verantwoord en $2^{\circ}$ het afval is niet op de juiste wijze afgevoerd of vernietigd.

Deze risico's zijn tegengesteld aan de risico's die zijn verbonden aan de goederenstroom met een positieve waarde. Wij beperken ons in het onderstaande tot de twee hoofdrisico's.

\section{ad 1 ontstaan van afval}

In de proces-industrie is het op grond van ervaringscijfers uit het verleden mogelijk om een norm te ontwikkelen voor de omvang en samenstelling van het afval. Aangezien afval een bekende (negatieve) waarde heeft, kan dit in de berekening van de kostprijs van het eindprodukt worden meegenomen. $\mathrm{Na}$ voltooiing van een produktieserie is het mogelijk om de werkelijke afvalkosten te beoordelen aan de hand van de voorcalcu- 


\section{MAB}

latorische norm, zodat bijzondere afwijkingen aan het licht komen en binnen de organisatie kunnen worden gerapporteerd.

Op grond van deze norm kan de omvang van het afval tot op zekere hoogte worden bewaakt. De registraties van de processen, zoals de produktieverantwoording en de kwijtingen van de magazijnen die de goedgekeurde produkten en de afvalstoffen ontvangen, lenen zich voor interne controle omdat deze van functioneel gescheiden personen afkomstig zijn. De technische relatie die bestaat tussen de input en de output van het proces, zal met enige tolerantie kunnen worden bewaakt door metingen of wegingen. Met dit geheel aan maatregelen is een redelijke zekerheid verkregen, dat alle ontstane afvalstoffen zijn verantwoord.

Spreken wij over milieubeheer in enge zin, dan zoeken wij naar mogelijkheden waarop het management het ontstaan van afval kan beïnvloeden. Naarmate meer informatie beschikbaar is over de diverse variabelen van het produktieproces, kan ook dit proces verfijnder worden aangestuurd in de door het management gewenste richting. Bij hantering van de negatieve verrekenprijs van het afval in de kostprijsadministratie is het mogelijk om de produktiechef verantwoordelijk te stellen voor de financiële gevolgen van het ontstaan van afval dan wel een bate toe te kennen indien de aansturing heeft geleid tot minder afval dan de gestelde norm. Uiteraard is een dergelijke verantwoordelijkheidsstelling slechts mogelijk indien een controle is opgezet met de functioneel gescheiden ontvangst in de magazijnen gereed produkt en afvalstoffen, aangevuld met een omspannende controle.

Wij zullen de mogelijkheden van de hantering van de kostprijs voor de bewaking van de afvalproduktie met een voorbeeld illustreren (zie volgende kolom).

Per kilogram bedraagt de kostprijs van de stof illustraline dus $f$ 15,--.

Met dit voorbeeld kunnen wij drie conclusies trekken:

- Er bestaat een (kwantitatieve) massa-balans tussen de input en de output. Ook de uitkom-
Kostprijs van stof illustraline:

Input:

$\begin{array}{rlrr}\text { gewicht } & \text { omschrijving } & \text { prijs/eenheid } & \text { waarde } \\ & & & \\ 100 \mathrm{~kg} & \text { grondstof A } & 2,- & 200- \\ 50 \mathrm{~kg} & \text { grondstof B } & 6,- & 300,- \\ 1 \mathrm{~kg} & \text { hulpstof C } & 150,- & 150,-\end{array}$

$151 \mathrm{~kg}$

4 uur machine $X Y Z$

8 uur arbeid

45,- $\quad 180,-$

35.- 280-

1.110

transport

$1.110,-$

Output:

$21 \mathrm{~kg}$

$10 \mathrm{~kg}$

verdamping

afval (afvoerkosten)

uitval (recycle-kosten)

9,- $\quad 90-$

$15,-\quad 300,-$

$100 \mathrm{~kg}$ gereed produkt $1.500,-$

sten van een produktie-charge kunnen met behulp van deze relatie worden bewaakt. Deze balans is echter niet zonder gevaren: het produkt dat verdampt kan water zijn, doch ook een gevaarlijk oplosmiddel dat niet wordt bewaakt.

- Indien bij de werkelijke produktiecijfers meer afval of uitval is gemeten, kan dit worden uitgedrukt in een financieel efficiency-resultaat waarvoor de produktiechef verantwoordelijk wordt gesteld. Uiteraard dienen de verantwoorde produktieciifers te worden gecontroleerd met gegevens van functioneel onafhankelijke afdelingen als het magazijn gereed-produkt, het afval-magazijn, en de afdeling kwaliteitscontrole.

- Verbetering van de produktietechnologie waarbij een groter rendement aan gereed produkt wordt nagestreefd (en dus minder afval wordt verkregen), leidt tot een lagere kostprijs.

De vorm waarin de informatie wordt verstrekt kan evenwel variëren van zuiver technisch (hoeveel- 


\section{MAB}

heden, fracties, chemische samenstelling) tot financieel. Beide vormen spelen in de administratieve organisatie een rol, doch de financiële registratie prevaleert omdat hiermede de bedrijfseconomische samenhangen op een omspannend niveau zichtbaar gemaakt kunnen worden vanuit de financiële administratie. De technische verbanden worden aldus in bedrijfseconomische termen zichtbaar, hetgeen vertrouwd terrein is voor de controller en de bedrijfsleiding. Het financiële effect van diverse milieumaatregelen wordt aldus ook meetbaar, er kan over worden gerapporteerd en de leiding kan zich een oordeel vormen over de resultaten van het milieubeleid.

\section{ad 2 afvoer van afval}

Nadat de volledigheid van het ontstane afval is vastgesteld, zal gecontroleerd moeten worden op de juiste afvoer. Door registratie van de afvalstoffen met behulp van een voorraadadministratie kan worden vastgesteld dat alle geproduceerde afval tot aan de afvoer kan worden getraceerd. Vaak is deze registratie partijgewijze opgezet. In het bovenbeschreven voorbeeld is het mogelijk de voorraad ook intracomptabel te volgen door de hantering van (negatieve) verrekenprijzen.

De volgende controlevraag is het vaststellen van de juiste wijze van afvoer. De kern van deze controle gaat uit van de aanwezigheid van bewijsstukken: van alle afgevoerde partijen kan een kwijting worden verkregen van de inzamelaar of verwerker (certificaat van afvoer of vernietiging). Dit is wettelijk geregeld voor de afvoer van chemisch afval.

\section{Afleggen van verantwoording}

Zodra de bedrijfsleiding binnen haar organisatie een milieuzorgsysteem operationeel heeft gemaakt, heeft zij het milieuvraagstuk onder controle. Een milieu-audit door een onafhankelijk onderzoeker kan leiden tot het uitspreken van een oordeel omtrent de kwaliteit van de in het bedrijf gehanteerde procedures, die relevant zijn voor de beheersing van de milieubelasting.

Aan de hand van de registraties van afvalstoffen kan, mits deze zijn ingebed in een goed stelsel van interne controle, een verslag worden opgesteld van de resultaten van het gevoerde milieubeleid. 8,9 Dit verslag zal, in de toekomst, ook een externe functie kunnen vervullen in de verantwoording jegens de overheid of de samenleving. Indien de administratieve organisatie en interne controle (bijvoorbeeld in de vorm van het bedrijfsinterne milieuzorgsysteem) goed is opgezet, en de bewijsstukken worden bewaard, dan zullen er ook voldoende aanknopingspunten aanwezig zijn voor een eventuele controle door externe controleurs. Vooralsnog zullen wij eerst alle aandacht moeten inzetten voor de invoering van de interne milieuzorgsystemen.

\section{Samenvatting en conclusies}

Wij hebben gezien dat de bedrijven die afvalstoffen produceren ook een administratieve organisatie kunnen opzetten met het oog op de besturing en beheersing van de bedrijfsprocessen en het afleggen van verantwoording. De afvalstoffen zelf zijn hierin ook object van besturing en controle. De maatschappelijk relevante vraag dat milieugevaarlijke stoffen moeten worden beperkt, en voor zover deze ontstaan volledig tot verantwoording komen, en tot een juiste methode van vernietiging leiden, kan vertaald worden naar concrete maatregelen van interne controle. Heeft het management de afvalstoffen onder controle, dan is aan een belangrijke voorwaarde voldaan voor de beheersbaarheid in maatschappelijk opzicht. De registraties van de stoffenstromen zijn hierin van belang, zij het dat de detaillering moet afhangen van de milieutechnische risico's. Onmisbaar zijn de andere maatregelen van interne controle zoals de controletechnische functiescheidingen. De oplossingen die het vak AO biedt, zijn aanvullend op de andere controlemaatregelen op milieuhygiënisch vlak. Ook blijft een stringent vergunningenstelsel in combinatie met inspecties nodig uit preventieve overwegingen.

De opstelling van een milieuverslag en de externe controle hierop is thans nog niet aan de orde, omdat eerst nog aandacht moet worden gegeven aan het bouwen van bedrijfsinterne milieuzorg- 
systemen. De aandacht zal zich voorlopig moeten toespitsen op de advisering en toetsing van de werking van deze milieuzorgsystemen.

Het vak administratieve organisatie kan met haar instrumentarium het volledigheidsprobleem van het ontstaan van afval onderkennen en de bewijsvoering aandragen voor de vaststelling van de juiste verwerkingswijze, en kan aldus een belangrijke bijdrage leveren aan de oplossing van onze milieuproblemen.

\section{Noten}

1 Bedrijfsinterne Milieuzorg, Notitie van de ministeries van Volkshuisvesting, Ruimtelijke Ordening en Milieubeheer en van Verkeer en Waterstaat, 's-Gravenhage, 1989.

2 Ministerie van Volkshuisvesting, Ruimtelijke Ordening en Milieubeheer 'VROM', Nationaal Milieubeleidsplan (NMP), vergaderstuk Nr. 21137 Tweede Kamer der Staten-Generaal, 's-Gravenhage, 1989.

3 Starreveld, R. W. (Red.), Bestuurlijke Informatieverzorging, deel 1, Alphen a/d Rijn, 1985.

4 Nederlandse Vereniging van Verwerkers van Chemische Afvalstoffen, Milieu- en Kwaliteitszorgsysteem voor de Houders van een Inzamel- en Bewaarvergunning krachtens de Wet Chemische Afvalstoffen, 1989.

5 Ministerie van Volkshuisvesting, Ruimtelijke Ordening en Milieubeheer 'VROM', Milieuzorg in samenspel, 's-Gravenhage. 1988.

6 Hafkamp, Dr. W. A., en anderen, Milieumanagement bij bedrijven, Rapport van de Raad voor het Milieu- en Natuuronderzoek nummer 36, 1989.

7 Buisman RA, J. H., en Van Marion RA, R. L., Milieu en Accountant, De Accountant, april 1989.

8 Bins-Hoefnagels, Mw. Drs. I. M. J., Molenkamp, dr. G. C., Wilschut RA, Prof. drs. K. P. G., De milieu-auditor en de accountant, De Accountant, juni 1986.

9 Blokdijk RA, Prof. J. H., Accountantscontrole en milieuauditing, De Accountant, oktober 1986. 